MATEC Web of Conferences 16, 03003 (2014)

DOI: $10.1051 /$ matecconf/ 20141603003

C Owned by the authors, published by EDP Sciences, 2014

\title{
Dynamic behaviour of rotary lip seal
}

\author{
M. El gadari ${ }^{1}$, M. Belhaq ${ }^{2}$ \\ ${ }^{1}$ ENSAM, University of Moulay Ismail, Meknès, Morocco \\ ${ }^{2}$ Mechanics Laboratory, University of Hassan II, Casablanca, Morocco
}

\begin{abstract}
We report on the dynamic behavior of a rotary lip seal by considering the interaction between lip, film and shaft roughness assumed to have a periodic form. The nonlinearities of stiffness and viscosity of the film are taken into account in a mass-spring-dumper model. Using the harmonic balance method, analytical prediction of the lip displacement is obtained, the frequency response is provided and the effect of the shaft undulation on the amplitude jumps of the lip displacement and on the film thickness fluctuations are discussed. The results have direct applications in reducing leakage that may occur between a smooth lip seal and a rough shaft.
\end{abstract}

\section{Introduction}

Lip seal device is the simplest and most widely used for sealing rotating shafts. Its role is to prevent leakage without causing wear. To study the thin film between shaft and lip surfaces, a Viscoelastohydrodynamic (VEHD) approach was proposed. In addition to the elasticity of the elastomer, the dissipative characteristic (viscoelastic) of the material was considered. An original study that addresses the dynamic of the lip seal was proposed in [1], showing a high correlation between the viscoelastic behavior of the material and the creation of the thin film. This approach is based on resolving Reynolds equation, coupled with lip mechanical behavior, by using Finite Element Analysis (FEA). In contrast, no analytical study has considered the effect of roughness of the shaft surface on the dynamics of the lip behavior and the film thickness.

In this work, we propose an analytical study on the dynamic of lip seal and squeezed film in interaction with rotating rough and rigid shaft, by considering a massspring-dumper model and taking into account the hydrodynamic behavior of the thin film and the dissipative characteristic of the seal. The Maxwell model is considered to describe the viscoelastic behavior of the seal. By assuming the rotary lip seal as a short bearing, the condition of squeeze film between the shaft and the seal can be reformulated, and therefore, the equivalent stiffness and damping coefficients to squeezed film can be determined $[2,3]$.

\section{Mechanical characterizations}

In order to characterize the viscoelastic law of the rotary lip seal, we propose to simulate the dynamic behavior by adopting "Proney" Series as described in [1], using FEA (Figure 1).

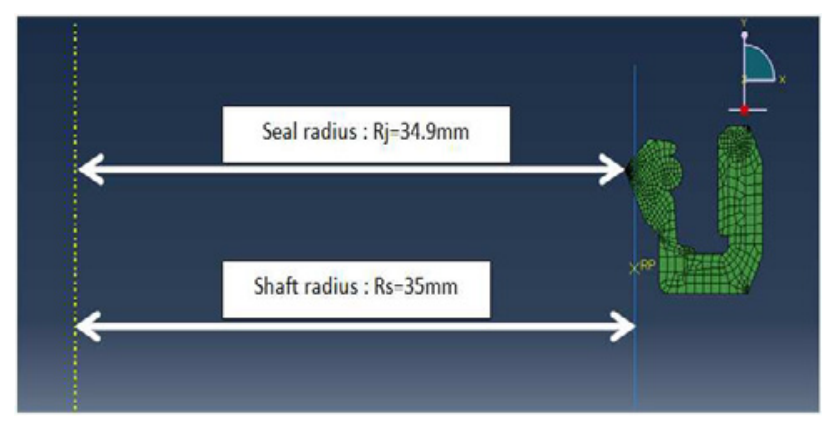

Figure.1. Finite Element Analysis with "Abaqus"

According to Stakenborg model [1], the parameters used in FEA simulation are chosen as follow: $\rho$ (elastomer density) $=1,46.10^{3} \mathrm{Kg} / \mathrm{m}^{3}$, Moony Rivlin" model (long term) $\mathrm{C}_{1}=-2.746 \mathrm{MPa}, \mathrm{C}_{2}=4.597 \mathrm{MPa}$, and Proney series (instantaneous) $\mathrm{g}_{1}=0.999$ and $\tau_{1}=0.003 \mathrm{~s}$. Shaft radius is $\mathrm{Rs}=35 \mathrm{~mm}$, seal radius $\mathrm{Rj}=34.9 \mathrm{~mm}$, the contact width $\mathrm{b}=0.07 \mathrm{~mm}$ and the maximum contact pressure $\mathrm{ps}=4.7 \mathrm{MPa}$.

The equation of motion for the FEA equivalent analytical model (Figure 2) is given by:

$$
\left\{\begin{array}{c}
\mathrm{m}_{2}\left(\ddot{\mathrm{z}}_{1}+\ddot{\mathrm{z}}_{2}\right)+\mathrm{K}_{\mathrm{r}}\left(\mathrm{z}_{1}+\mathrm{z}_{2}\right)+\eta \dot{\mathrm{z}}_{2}=\mathrm{f}(\mathrm{t}) \\
\mathrm{K}_{\infty} \mathrm{z}_{1}=\eta \dot{\mathrm{z}}_{2}
\end{array}\right.
$$


where $z_{1}$ is the elastic displacement of elastomer, $z_{2}$ is the damping displacement, $\mathrm{m}_{2}$ is the equivalence mass of lip seal, $K_{\infty}$ is the equivalent stiffness of elastomer, $\eta$ is the damping factor, $K_{r}$ is the equivalent spring stiffness, and $\mathrm{f}(\mathrm{t})$ is the dynamic force applied to system.

We define Laplace transformation of function $\mathrm{g}(\mathrm{t})$ by

$G(s)=\int_{-\infty}^{+\infty} g(t) \cdot e^{-s \cdot t} d t$

By using Laplace transformation and $\mathrm{z}=\mathrm{Z}_{1}+\mathrm{z}_{2}$, we deduce: $\frac{F(s)}{Z(s)}=\frac{\eta m_{2} s^{3}+K_{\infty} m_{2} s^{2}+\eta\left(K_{r}+K_{\infty}\right) s+K_{\infty} K_{r}}{K_{\infty}+\eta s}$

such as: $s=j \omega, j^{2}=-1$ and $\omega$ is the pulsation.

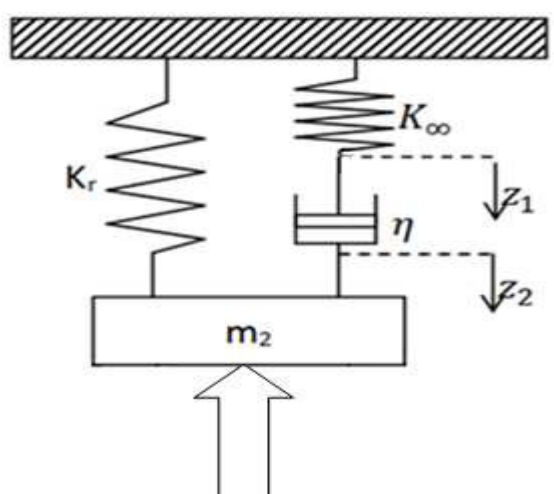

Figure.2. Rotary lip seal analytical model

Thus, the stiffness modulus and argument are given by

$$
\begin{gathered}
\left|\frac{F(s)}{Z(s)}\right| \\
=\sqrt{\frac{\left(\eta\left(K_{r}+K_{\infty}\right) \omega-\eta m_{2} \omega^{3}\right)^{2}+\left(K_{\infty} K_{r}-K_{\infty} m_{2} \omega^{2}\right)^{2}}{K_{\infty}{ }^{2}+\eta^{2} \omega^{2}}} \\
\operatorname{Arg}\left(\frac{F(s)}{Z(s)}\right)=\operatorname{Arctan}\left(\frac{\eta\left(K_{r}+K_{\infty}\right) \omega-\eta m_{2} \omega^{3}}{K_{\infty} K_{r}-K_{\infty} m_{2} \omega^{2}}\right) \\
-\operatorname{Arctan}\left(\frac{\eta \omega}{K_{\infty}}\right)
\end{gathered}
$$

By comparing the analytical results and FEA simulation (Figure 3), we can identify the Maxwell parameters of the rotary lip seal.

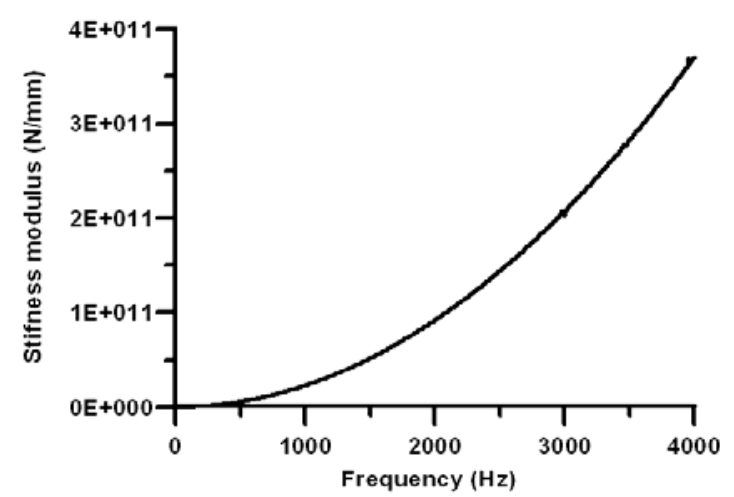

(a) Stiffness modulus by FEA simulation

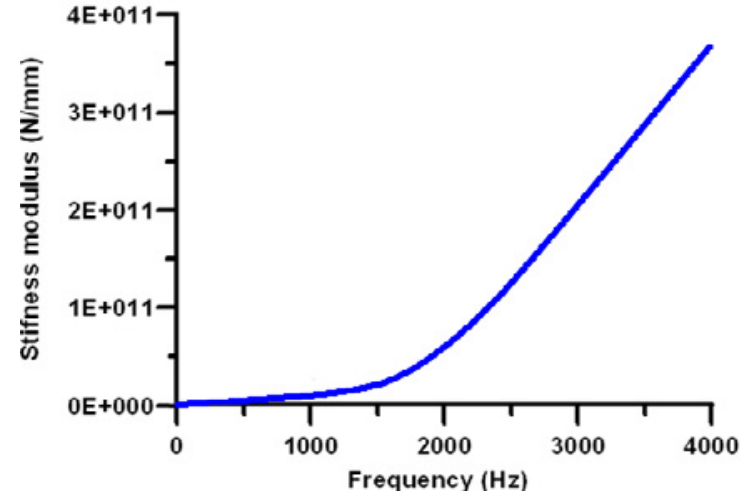

(b) Stiffness modulus with analytical model

Figure.3.Comparison between analytical and FEA model

Thus, we conclude the equivalent lip seal mass $\mathrm{m}_{2}=0,55.10^{6} \mathrm{Kg}$, the spring stiffness $\mathrm{K}_{\mathrm{r}}=34.106 \mathrm{~N} / \mathrm{m}$, the elastomer stiffness $\mathrm{K}_{\infty}=71,4.106 \mathrm{~N} / \mathrm{m}$ and the dumper elastomer coefficient $\eta=108 \mathrm{~N} . \mathrm{s} / \mathrm{m}$.

In order to verify the numerical results, we have confirmed in Figure 4 the spring and elastomer mechanical characterizations by comparing the stiffness argument of each model.

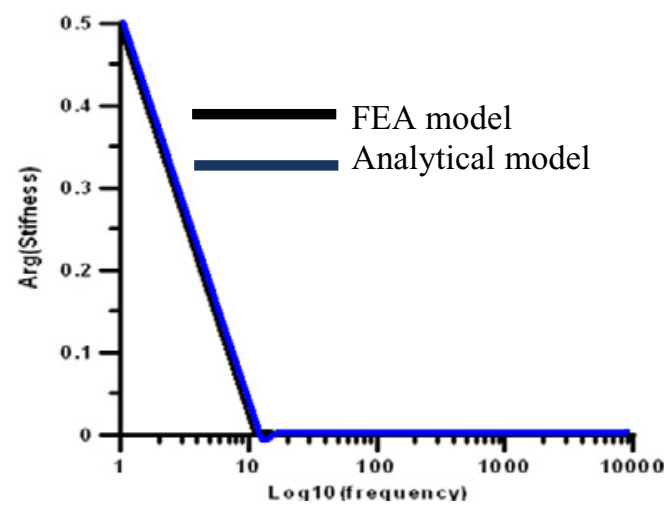

Figure.4. Stiffness argument by using FEA and analytical model

As shown in Figure 4, there is a good correlation between the analytical model and the numerical results obtained using FEA.

\section{Equation of motion}

The simplified mechanical system with 2 degrees of freedom that models the movement of the lip seal is shown in Figure 5. The equations of motion can be written as

$$
\left\{\begin{array}{c}
\mathrm{m}_{2}\left(\ddot{\mathrm{z}}_{1}+\ddot{\mathrm{z}}_{2}\right)+\mathrm{K}_{\mathrm{r}}\left(\mathrm{z}_{1}+\mathrm{z}_{2}\right)+\eta \dot{\mathrm{z}}_{2}=\mathrm{K}_{2} \mathrm{~h}+\eta_{2} \dot{\mathrm{h}} \\
\mathrm{K}_{\infty} \mathrm{z}_{1}=\eta \dot{\mathrm{z}}_{2}
\end{array}\right.
$$

where $\mathrm{h}(\mathrm{t})$ is film thickness, $\mathrm{K}_{2}$ is the equivalent stiffness of squeeze film, $\eta_{2}$ is the damping factor equivalent, $U$ is shaft velocity, $\mathrm{R}$ is shaft radius and $\omega$ is shaft rotation speed. 


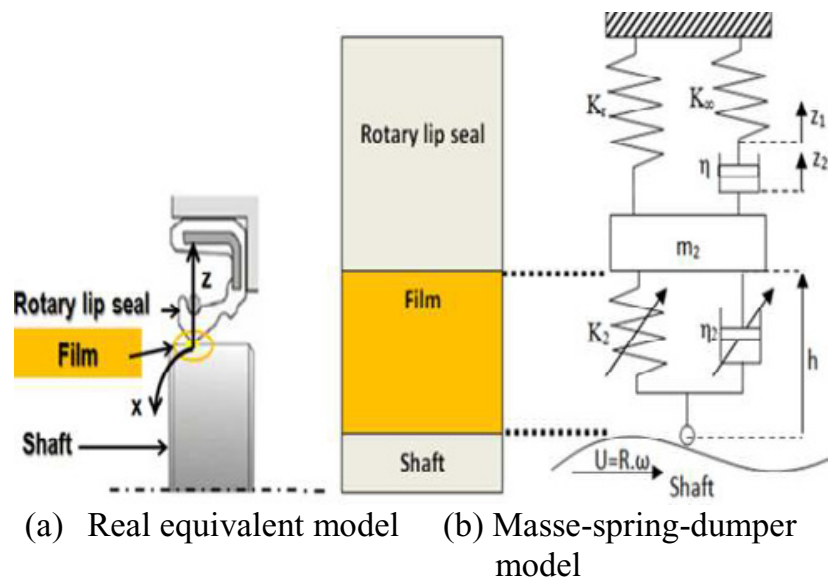

Figure 5. Analytical model of rotary lip seal

We consider the nonlinear case by introducing the nonlinear rheological model of the fluid as in [3]. In this case the coefficients of stiffness and viscosity of the fluid can be written as

$$
\mathrm{K}_{2}=\frac{2 \mu R b^{3} \text { e. } \omega}{\left(c^{2}-\mathrm{e}^{2}\right)^{2}}, \eta_{2}=\frac{\mu \mathrm{Rb}^{3} \pi}{2\left(\mathrm{c}^{2}-\mathrm{e}^{2}\right)^{\frac{3}{2}}}
$$

where

$$
\mathrm{c}=\mathrm{e}+\delta, \quad \delta=\mathrm{z}_{1}+\mathrm{z}_{2}, \quad \mathrm{~h}=\mathrm{e}(1+\cos (\omega \mathrm{t}))+\delta
$$

such as e is the shaft misalignment and $\delta$ is total lip displacement. The nonlinearity of the rheological model comes from the results given in [3]. By considering $\mathrm{z}=\mathrm{z}_{1}+\mathrm{z}_{2}$ and developing $\mathrm{K}_{2}$ and $\eta_{2}$ to order 3 , we obtain

$$
\begin{gathered}
\mathrm{K}_{2}=\mathrm{K}_{20}-\mathrm{K}_{21}\left(\mathrm{z}-\mathrm{e}_{1}\right)+\mathrm{K}_{22}\left(\mathrm{z}-\mathrm{e}_{1}\right)^{2} \\
-\mathrm{K}_{23}\left(\mathrm{z}-\mathrm{e}_{1}\right)^{3}+\mathrm{o}\left(\left(\mathrm{z}-\mathrm{e}_{1}\right)^{3}\right) \\
\begin{array}{c}
\eta_{2}=\eta_{20}-\eta_{21}\left(\mathrm{z}-\mathrm{e}_{1}\right)+\eta_{22}\left(\mathrm{z}-\mathrm{e}_{1}\right)^{2}-\eta_{23}\left(\mathrm{z}-\mathrm{e}_{1}\right)^{3} \\
+\mathrm{o}\left(\left(\mathrm{z}-\mathrm{e}_{1}\right)^{3}\right)
\end{array}
\end{gathered}
$$

where

$\mathrm{K}_{20}=\frac{\mathrm{K}_{0}}{\left(\mathrm{e}_{1}^{2}+2 \mathrm{e}_{1} \mathrm{e}\right)^{2}}$

$K_{21}=\frac{4 K_{0}\left(e+e_{1}\right)}{\left(e_{1}^{2}+2 e_{1} e\right)^{3}}$

$\mathrm{K}_{22}=\frac{-4 \mathrm{~K}_{0}}{\left(\mathrm{e}_{1}^{2}+2 \mathrm{e}_{1} \mathrm{e}\right)^{3}}+\frac{24 \mathrm{~K}_{0}\left(\mathrm{e}+\mathrm{e}_{1}\right)^{2}}{\left(\mathrm{e}_{1}^{2}+2 \mathrm{e}_{1} \mathrm{e}\right)^{4}}$

$\mathrm{K}_{23}=\frac{192 \mathrm{~K}_{0}\left(\mathrm{e}+\mathrm{e}_{1}\right)^{3}}{\left(\mathrm{e}_{1}^{2}+2 \mathrm{e}_{1} \mathrm{e}\right)^{5}}-\frac{72 \mathrm{~K}_{0}\left(\mathrm{e}+\mathrm{e}_{1}\right)}{\left(\mathrm{e}_{1}^{2}+2 \mathrm{e}_{1} \mathrm{e}\right)^{4}}$

$\eta_{20}=\frac{\eta_{0}}{\left(e_{1}^{2}+2 e_{1} e\right)^{\frac{3}{2}}}$

$\eta_{21}=\frac{3 \eta_{0}\left(e+e_{1}\right)}{\left(e_{1}^{2}+2 e_{1} e\right)^{5 / 2}}$

$\eta_{22}=\frac{-3 \eta_{0}}{\left(\mathrm{e}_{1}^{2}+2 \mathrm{e}_{1} \mathrm{e}\right)^{\frac{5}{2}}}+\frac{15 \eta_{0}\left(\mathrm{e}+\mathrm{e}_{1}\right)^{2}}{2\left(\mathrm{e}_{1}^{2}+2 \mathrm{e}_{1} \mathrm{e}\right)^{\frac{7}{2}}}$

$\eta_{23}=\frac{105 \eta_{0}\left(e+e_{1}\right)^{3}}{2\left(e_{1}^{2}+2 e_{1} e\right)^{9 / 2}}-\frac{30 \eta_{0}\left(e+e_{1}\right)}{\left(e_{1}^{2}+2 e_{1} e\right)^{7 / 2}}$

$\mathrm{K}_{0}=2 \mu R \mathrm{Rb}^{3}$ e. $\omega, \eta_{0}=\mu \mathrm{Rb}^{3} \pi$ in which $\mathrm{e}_{1}$ is the displacement of Taylor series verifying $\left|z-e_{1}\right|<<1$. By using the harmonic balance method, we assume that

$$
\left\{\begin{array}{l}
\mathrm{z}=\mathrm{z}_{10}+\mathrm{z}_{11} \cos (\omega \mathrm{t})+\mathrm{z}_{12} \sin (\omega \mathrm{t}) \\
\mathrm{z}_{2}=\mathrm{z}_{20}+\mathrm{z}_{21} \cos (\omega \mathrm{t})+\mathrm{z}_{22} \sin (\omega \mathrm{t})
\end{array}\right.
$$

Thus Equation (5) becomes:

$$
\left\{\begin{array}{c}
\mathrm{m}_{2} \ddot{\mathrm{z}}+\mathrm{K}_{\mathrm{r}} \mathrm{z}+\eta \dot{\mathrm{z}}_{2}=\left\{\mathrm{K}_{20}-\mathrm{K}_{21}\left(\mathrm{z}-\mathrm{e}_{1}\right)+\mathrm{K}_{22}\left(\mathrm{z}-\mathrm{e}_{1}\right)^{2}\right. \\
\left.-\mathrm{K}_{23}\left(\mathrm{z}-\mathrm{e}_{1}\right)^{3}\right\}(\mathrm{z}+\mathrm{e}(1+\cos [\omega \mathrm{t}]))+ \\
\left\{\eta_{20}-\eta_{21}\left(\mathrm{z}-\mathrm{e}_{1}\right)+\eta_{22}\left(\mathrm{z}-\mathrm{e}_{1}\right)^{2}-\eta_{23}\left(\mathrm{z}-\mathrm{e}_{1}\right)^{3}\right\} \\
\quad(\dot{\mathrm{z}}-\mathrm{e} \cdot \omega \cdot \sin [\omega \mathrm{t}]) \\
\mathrm{K}_{\infty} \mathrm{z}=\eta \dot{\mathrm{z}}_{2}+\mathrm{K}_{\infty} \mathrm{z}_{2}
\end{array}\right.
$$

where $\omega_{0}=\sqrt{K_{r} / m_{2}}$.

\section{Validation of the analytic approach}

In order to validate the analytic model, the result was compared to simulations made in [1]. By adopting the same mechanical characteristics of the lip and lubricant, the minimum and maximum film thickness of each approach give a good concordance with a marginal gap about $2 \%$ and $15 \%$ as shown in Figure 6.

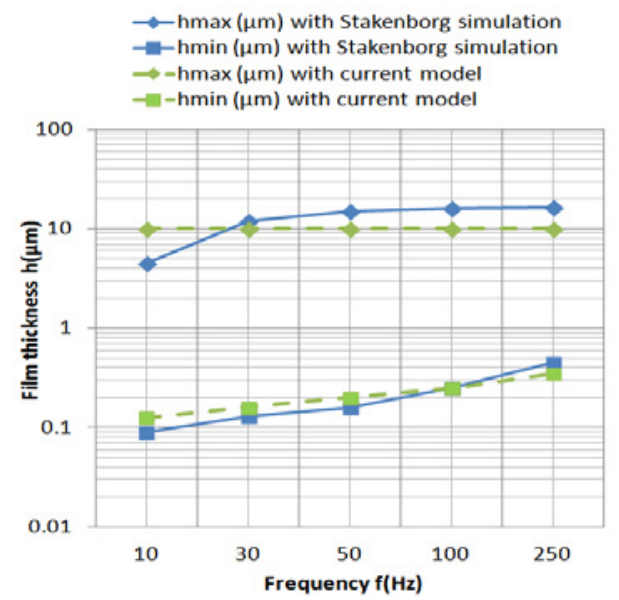

Figure 6. Comparison between current model and Stakenborg approach [4]

In this section, we focus on the dynamic of the lip seal in lubricated rough contact with shaft surface. Note that in [1] it was assumed the roundness and misalignment of smooth shaft. Practically, the lashing effect is about $100 \mathrm{~Hz}$ as excitation frequency instead of $10 \mathrm{GHz}$ for roughness effect. Because of numerical limitation no study was proposed to explain the influence of shaft roughness on lip performance.

The similarity between misalignement case and roughness shaft is shown in Figure 7 . By using the following assumptions, we perform the calculation of lip displacement (Figure 8) and deducing the film thickness: $\tilde{h}$ is shaft amplitude roughness instead of eccentricity in 
misalignment case, $\Omega=2 \pi U / \lambda$ is roughness pulsation and $\lambda$ is the wavelength of shaft roughness.
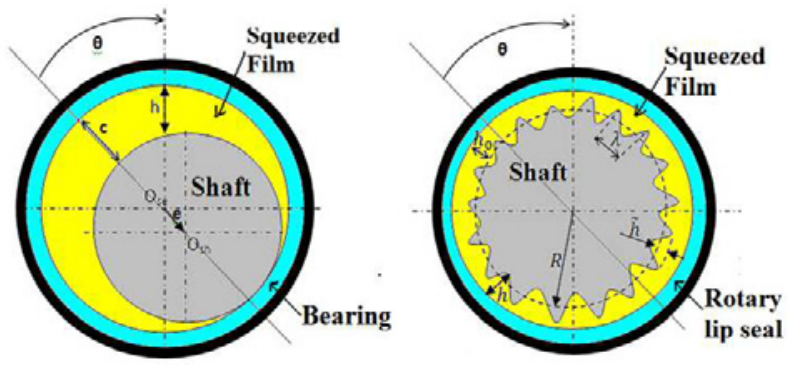

(a) $h=e(1+\cos (\omega t))+z$

(b) $h=\tilde{h}(1+\cos (\Omega t))+z$

Figure 7. Comparison between film thicknesses in bearing squeezed film assumptions and current model

Figure 8 shows the effect of shaft undulation on the lip displacement and film thickness. It can be seen that the amplitude of the roughness of the shaft and the excitation has a significant influence on the amplitudes of the jumps of the lip deformation in the direction of start and stop and on the location of the jump. Indeed, we conclude that as the roughness is increased, the jump in starting regim Hs decreases and shifts toward higher frequencies.

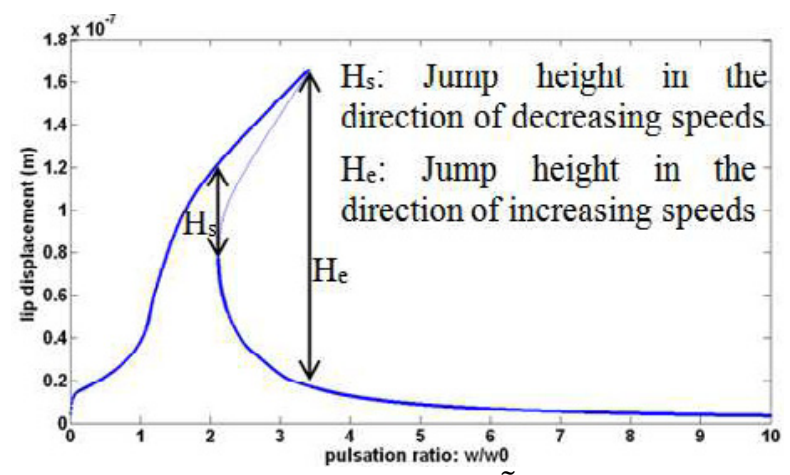

(a) Shaft roughness: $\tilde{h}=0.5 \mu m$

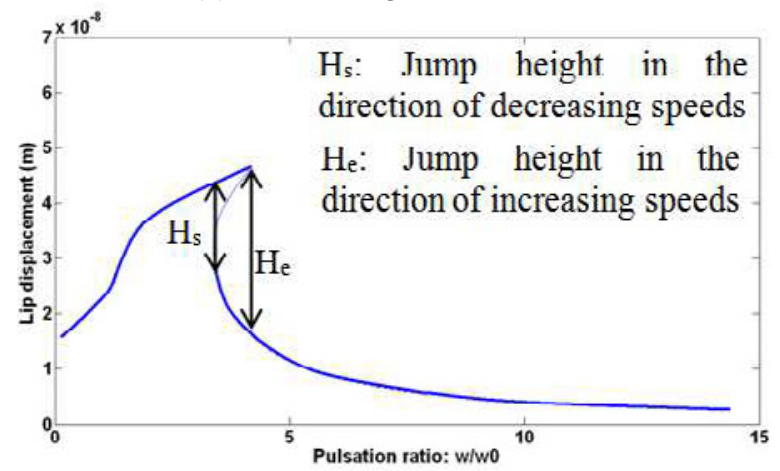

(b) Shaft roughness: $\tilde{h}=0.25 \mu \mathrm{m}$

Figure 8. Lip displacement by varying shaft roughness amplitude

\section{Conclusions}

We have studied the dynamic behavior of lip displacement in interaction with squeezed film excited by shaft. This problem has been treated in $[1,4,5,6]$ by assuming the viscoelastic behavior of the elastomer with Proney series and considering the excitatory effect of shaft misalignement or roundness. The effect of the shaft roughness as a source of high frequency excitation of the thin film was not analyzed.

This study proposed an original analytical treatment taking into account the nonlinearities in stiffness and viscosity of the squeeze film. Thus, with the proposed model, our results have been validated by comparing to Stakenborg approach and considering shaft misalignment excitation. Analogically, a shaft undulation perturbation was studied. The results have shown the effect of shaft roughness on the jumps phenomenon of the lip displacement which influences the squeezed film and leakage.

\section{References}

1. M.J.L. Stakenborg, H.J. Van Leeuwen, Viscoelastohydrodynamic (VEHD) lubrification in radial lip seals: Part 1- Steady state dynamic viscoelastic seal behavior, Transactions of the ASME. 112 (1990) 578-583.

2. E.J. Gunter, Design of non linear squeeze-film dampers for aircraft engines, Journal of Lubrication Technology. 99 (1977) 57-64.

3. A. Younan, P. Allaire, A review of tilting pad bearing theory timothy dimond, International Journal of Rotating Machinery. 23 (2011) 1-23.

4. H.J. Van Leeuwen, M.J.L. Stakenborg, Viscoelastohydrodynamic (VEHD) lubrification in radial lip seals: Part 2- Fluid film formation, Transactions of the ASME. 112 (1990) 584-592.

5. M. Silvestri, E. Prati, A. Tasora, Radial lip seals efficiency under dynamic operating conditions, International Conference on Tribology, Parma, (2006).

6. A. Lucko, S. Meyer, V.M. Wollesen, Finite element analysis of a rotary shaft lip type seal operating with a dynamic eccentricity of the shaft, Research papers of IAg. Eng. LUA \& LU of Ag. 37 (2005) 94-109.

\section{Acknowledgments}

The authors are grateful to the Technical Centre for the Mechanical Industry "CETIM-Nantes", and Pprime Institute (University of Poitiers) that supported this work. 